\title{
Job Related Stress and Employment of People with Mental Illness: A Catch 22
}

\author{
Poornima Mahindru $^{1} \cdot$ Manoj Kumar Sharma ${ }^{1} \cdot$ Santosh Kumar Chaturvedi $^{2}$
}

Received: 15 February 2016/Accepted: 28 March 2016/Published online: 20 April 2016

(c) Springer India Pvt. Ltd. 2016. This article is published with open access at Springerlink.com

\begin{abstract}
A roaring hike in stress related psychiatric symptoms is being noticed in the employees of corporate sectors. However, the industries are not well equipped to provide adequate medical help to these individuals, leading them to seek help on their own from outside. Due to the lack of collaboration with the mental health sector, mental health professionals face various dilemmas in evaluating and treating employees of corporate sector. This communication throws light on some of these professional ethical issues encountered by mental health professionals, and, recommendations to ease out these existing difficulties.
\end{abstract}

Keywords Job related stress - Mental health professionals - Ethical dilemmas · Psychiatric evaluation

Corporate Sectors are the biggest contributors for the economic stability of the country. They are the largest platform to provide the employment to the general public. They help people grow up as a professional and help them improve their lifestyle in exchange of their contribution for the financial growth of their companies. However, it does not come easy. It requires a lot of physical and mental investment which becomes challenging for the employees. Sometimes these challenges act as motivators and sometimes they take the shape of stressors due to the pressures encountered by demanding jobs. This is bound to have an impact on a person with mental illness.

Poornima Mahindru pmahindru86@gmail.com

1 Department of Clinical Psychology, NIMHANS, Bengaluru, Karnataka, India

2 Department of Psychiatry, NIMHANS, Bengaluru, Karnataka, India
The workplace is one of the key environments that affect our mental wellbeing and health. There is an acknowledgement and growing awareness of the role of work in promoting or hindering mental wellness and its corollary-mental illness. Although it is difficult to quantify the impact of work alone on personal identity, selfesteem and social recognition, it is expected that the workplace environment can have a significant impact on an individual's mental well-being.

Recent epidemiological studies show the prevalence rate of psychiatric disorders in Indian industrial population varying from 14 to $51.7 \%$ as compared to community where it ranges from 0.95 to $13 \%$ [1-3]. According to the Western reports these prevalence rates can be up to as high as $74 \%$ [4]. Though these studies were conducted using small samples and without any specific diagnostic assessments, the outcome of these studies is the matter of concern. The prevailing psychiatric symptoms in corporate sector are found to be associated with perceived increased stress levels at work, dysfunctional interpersonal relationships, increased job pressure, greater responsibility without authority, and feeling of insecurity, career problems and pressure for production. However, it is not clear that these factors act as a cause or effect of the psychiatric symptoms [1].

Employers experience expensive consequences of mental illness through absenteeism, lower productivity, disability, accidents and the inappropriate use of medical services. Seeing this grave existing situation, many organizations have come up with the policies to deal with the mental fitness of the employees.

Work is important for mental health and indeed the right to work in just and favorable conditions and with protection from unemployment is enshrined in the United Nations Universal Declaration of Human Rights (Article 23) [5]. 
Work produces personal and health benefits, while the absence or loss of work can potentially damage a person's mental health [6].

World Health Organization's mental health policies and programs in the workplace recognizes the importance of mental health and talks about the evaluation, intervention modules and the re integration of the employees suffering from mental ill health [7]. However, the evaluation of mental fitness requires expertise and the employees need to be out sourced for the expert evaluation.

In clinical practice, one comes across the individuals who present with adjustment related issues at work. They are referred for the evaluation of their mental fitness and sometimes they seek help on their own.

When individuals employed in the industry are referred to the mental health professional for evaluation, a lot of ethical dilemmas come along with it. In a developing country like India, where there is a dearth of set guidelines for reference and disclosure of patients' health reports, the dilemma tends to increase from questioning the authenticity of the referral made to how much the reports will be used in favor of the employee or the employer.

Case Scenario A person in late twenties working in a multinational company is assigned a new project. This individual perceives the project to be stressful and presents with the depressive symptoms and takes medical leave from the company. However, sitting at home without any work also becomes frustrating for this person. Due to these adjustment issues, this person seeks help from mental health professional team. During the course of psychiatric treatment, the company demands for the mental health fitness certificate before he can resume work.

This case scenario makes us ponder on the various ethical issues involved. For example,

- The mode of reference is questionable. Many questions arise in terms of how and who should make the referral. Should the treating team be contacted directly by Human Resource Professionals or it should come through the employee?

- As we are living in a tech savvy era, how much the authenticity of the request through emails should be valued? In multinational companies, the issue arises as the HR professionals cannot be contacted through phone and most of the communications happen through emails.

What is the validity of the request from an unknown email id requesting for a medical fitness certificate claiming to be a HR professional and having all the good intentions to help the employee?

- How much disclosure of the mental state of the individual is adequate? At times there are people with mild coping deficits that make him/her vulnerable towards excessive stress and the communication of this finding may lead to unemployment, which merely aggravates his/her stress. In Mental Health Care Bill, permission of mental health records and reports has been included. Reports can be sent to the company only with written consent/approval of the employee who is competent [8]. Therefore; the dilemma arises regarding the benefits attached with the disclosure.

- Once the evaluation has been carried out, questions arise as to how the reports need to be provided? Should it be given to the employee directly or should it be emailed to the HR professional from where the request has come or should it be posted to the head office of the company. Once again the authenticity of the email can be questioned.

- Also, there is still an uncertainty regarding the frequency of the follow ups in order to track the progress or consequences of the report submitted. Should there be fixed guidelines? The follow ups are important considering the apprehension regarding the usage of the reports and how the company is helping in reintegration of the individual.

- Moreover, as confidentiality is one of the most important ethical issues, there is a need of proper guidelines regarding the accessibility and the documentation of the report.

- Lastly, the question arises regarding the recommendation of the vocational rehabilitation. The global guidelines and mental health care bill direct the employers to rehabilitate the employees who are not medically fit. However, the absenteeism of the employee, decreased productivity and presenteeism turn out to be quite taxing for the employer [2].

Additionally, for the employee, the adequate place and time of the supported employment becomes quandary which might lead to the further damage to his selfesteem.

These unanswered questions give rise to the dilemma in the mental health professional's mind resulting in the delay and the long waiting period for the individual to resume his job. As the corporate sector is picking up the pace in India, the need of the hour is to come up with the global ethical guidelines in collaboration with the mental health sector to provide benefits to the working individuals. The disclosure of the mental health status should happen in the consultation with the mental health experts so that mental wellbeing of the employee is assured. The Indian Industries Act and National Mental Health Programme advocate the periodic assessment and need to address mental health issues across various occupations. However, it is com- 
monly observed that the mental health problems are neither subjected to surveillance nor notification by these programmes, hence, limiting their priority from industrial health management [9]. Therefore, a transparent system is required to keep a check on the implementation of the workplace mental health policies that are being proposed by these programmes. An intersectoral coordination between ministries of health and the labor is essential to align national health policies in workplace.

Furthermore, the companies should be well equipped to identify the early signs of job related stress symptoms. The screening for mental health can be integrated in the periodic health examination system in the industry and the industry management can be urged to set up a multidisciplinary committee to oversee the implementation of occupational mental health and health promotion program. Employee Assisted Programs should be made and implemented in consultation with mental health professionals. They should be open for the collaboration with the mental health professionals to provide required assistance to their employees and should be able to outsource them to seek help for medication and intensive psychotherapy to manage the job related stress and psychiatric symptoms.

Open Access This article is distributed under the terms of the Creative Commons Attribution 4.0 International License (http://crea tivecommons.org/licenses/by/4.0/), which permits unrestricted use, distribution, and reproduction in any medium, provided you give appropriate credit to the original author(s) and the source, provide a link to the Creative Commons license, and indicate if changes were made.

\section{References}

1. Dutta S, Kar N, Thirthalli J, Nair S. Prevalence and risk factors of psychiatric disorders in an industrial population in India. Indian $\mathbf{J}$ Psychiatry. 2007;49(2):103.

2. Chaturvedi SK, Kalyanasundaram S, Jagadish A, Prabhu V, Narasimha V. Detection of stress, anxiety and depression in IT/ ITES professionals in the Silicon Valley of India: a preliminary study. Prim Care Community Psychiatry. 2007;12(2):75-80.

3. Kiran Kumar PK, Jayaprakash K, Francis NP. Psychiatric morbidity in industrial workers of South India. J Clin Diagn Res. 2011;5:921-5.

4. Kar N, Dutta S, Patnaik S. Mental health in an Indian industrial population: screening for psychiatric symptoms. Indian J Occup Environ Med. 2002;6:86-8.

5. United Nations (1948). Universal declaration of human rights. Adopted and proclaimed by UN General Assembly Resolution 217 A (III).

6. Huxley P. Work and mental health: an introduction to the special section. J Ment Health. 2001;10(4):367-72.

7. World Health Organization, Funk M. Mental health policies and programmes in the workplace. Geneva: World Health Organization; 2005.

8. PRS legislative research, bill summary, the mental health care bill. http://www.prsindia.org/uploads/media/MentalHealth.

9. Sukumar G, Kupatira K, Gururaj G. Feasibility of integrating mental health and noncommunicable disease risk factor screening in periodical medical examination of employees in industries: an exploratory initiative. Indian J Occup Environ Med. 2015;19(1):19. 